\title{
Well-being and academic achievement in secondary school pupils: The unique effects of burnout and engagement
}

\author{
Irene Cadime ${ }^{a,}{ }^{*}$, Alexandra Marques Pinto ${ }^{b}$, Sara Lima ${ }^{c}$, Sara Rego ${ }^{c}$, \\ Joana Pereira ${ }^{\mathrm{c}}$, Iolanda Ribeiro ${ }^{\mathrm{c}}$ \\ ${ }^{a}$ Research Centre on Child Studies, University of Minho, Portugal \\ ${ }^{\mathrm{b}}$ Faculty of Psychology, University of Lisboa, Portugal \\ ${ }^{\mathrm{c}}$ School of Psychology, University of Minho, Portugal
}

\section{A R T I C L E I N F O}

\section{Article history:}

Available online 27 October 2016

\section{Keywords:}

Well-being

Academic achievement

Secondary school

Pupils' burnout

Pupils' engagement

\begin{abstract}
A B S T R A C T
The main goal of this study was to examine the relationship among burnout, engagement, well-being, and academic performance in Portuguese secondary school pupils. The existence of gender related differences in these relationships was also investigated. The sample was composed of 489 pupils who attended an academic track at secondary school. Results of multi-group structural equation modelling indicated that higher levels of cynicism towards studies were associated with lower academic achievement. Exhaustion was not uniquely related to the adolescents' academic achievement or well-being. However, higher levels of engagement, namely dedication and vigour, were related to higher levels of wellbeing. Moreover, vigour was also uniquely associated with academic achievement. The results were similar for boys and girls. Implications for intervention and future research are discussed.
\end{abstract}

(c) 2016 The Foundation for Professionals in Services for Adolescents. Published by Elsevier Ltd. All rights reserved.

Adolescence has long been recognized as a period of vulnerability to stress, which may contribute to stress-related health problems (e.g., Compas, Orosan, \& Grant, 1993). The recent American Psychological Association (2014) Stress in America survey revealed that teenagers reported stress levels they perceived as being unhealthy, and that the two most commonly reported sources of stress were school (83\%) and gaining entry into university or deciding what to do after secondary school (69\%). The academic transition to secondary school also requires youths to interact with a new and larger peer group and to manage greater academic pressures (Suldo, Shaunessy, Thalji, Michalowski, \& Shaffer, 2009). In Portugal, the secondary school years are a critical and demanding period: (a) pupils must choose a specific area of studies (specialization within an academic or a vocational track), which can determine their later academic and professional trajectories; (b) entering university depends largely on the average mark obtained at secondary school and the number of university admissions is limited, which can lead to competitiveness among pupils and an extreme focus on achievement. Longitudinal studies conducted in other countries found that about one third of the students showed an increase in their burnout levels in the transition to secondary school and that this increase was mainly observed in the academic (non-vocational) track, due to its demands and its focus on comparison (Salmela-Aro \& Tynkkynen, 2012; Salmela-Aro \& Upadyaya, 2014a). Despite being

\footnotetext{
* Corresponding author. Centro de Investigação em Estudos da Criança, Instituto de Educação, Universidade do Minho, Campus de Gualtar, 4710-057 Braga, Portugal.

E-mail address: irenecadime@ie.uminho.pt (I. Cadime).
} 
confronted with highly stressful situations, most people do not present burnout symptoms and instead maintain high engagement with their work or studies. Both burnout and engagement can therefore be accompanied by positive or negative outcomes. The aim of this study was to investigate the relationships among burnout, engagement, academic achievement and well-being in Portuguese adolescents attending an academic track in secondary school.

\section{Pupils' burnout, engagement, academic success and well-being}

The study of school burnout mirrors that of professional burnout (Maslach, Schaufeli, \& Leiter, 2001). Students in a state of burnout feel exhausted, adopt a cynical and withdrawn attitude towards their studies, and end up losing their sense of efficacy as students when confronted with academic demands (Schaufeli, Martinez, Marques Pinto, Salanova, \& Bakker, 2002). Some studies have challenged this three dimensional view of burnout and have considered exhaustion and cynicism as its core dimensions (Choi, 2013; Green, Walkey, \& Taylor, 1991; Qiao \& Schaufeli, 2011).

Several studies have found a negative association between burnout and academic success (e.g., Dahlin, Joneborg, \& Runeson, 2007; Schaufeli, Martinez, et al., 2002) in college students, but this relationship was not always found across different samples. For instance, in a cross-national study by Schaufeli, Martinez, et al. (2002) and Schaufeli, Salanova, et al. (2002) conducted with university students from Portugal, Spain and the Netherlands, exhaustion and cynicism were negatively correlated with academic success (measured as passing exams), but only in the Spanish sample and the relationship was weak. Findings regarding the relationship between school related burnout and academic achievement in adolescents are also inconsistent, with some studies revealing an association between high levels of burnout and low school achievement (e.g., Salmela-Aro, Kiuru, Leskinen, \& Nurmi, 2009), while in others no relationship has been observed (e.g., Wang, Chow, Hofkens, \& Salmela-Aro, 2015). A relationship between burnout and well-being has also frequently been reported for college students (Choi, 2013; Dahlin \& Runeson, 2007). Research with secondary school pupils has related burnout mainly with ill-being manifestations, such as depressive symptoms (e.g., Salmela-Aro, Savolainen, \& Holopainen, 2009).

Work engagement was initially assumed to be the positive antipode of burnout (Maslach \& Leiter, 1997), however more recent theorization and research have come to reveal that rather than being two opposite poles, burnout and engagement are independent, yet negatively correlated phenomena (e.g., Schaufeli \& Bakker, 2004; Schaufeli, Salanova, González-Romá, \& Bakker, 2002). Engagement is a positive and persistent cognitive-affective state, that encompasses vigour (a state of mental vitality and resilience, a will to invest efforts and persist through adverse situations), dedication (feelings of pride towards one's assignment, and finding it meaningful), and absorption (total immersion in and concentration on the task and a subjective perception of time flying) (Schaufeli, Salanova, et al., 2002). Nevertheless, some studies have given priority to simply measuring the vigour and dedication dimensions of engagement, which, on a par with burnout dimensions exhaustion and cynicism, are considered the core dimensions of engagement (e.g., Salanova, Schaufeli, Martínez, \& Bresó, 2010).

Similarly to burnout, the interest in the study of engagement has been extended from work settings to the academic domain and several studies have demonstrated that the engagement dimensions were negatively correlated with the burnout dimensions (Schaufeli, Martinez, et al., 2002; Schaufeli, Salanova, et al., 2002). This approach to pupils' engagement is rooted and more prevalent in Europe, whereas in North America a different approach that conceptualizes school engagement as encompassing a behavioural, cognitive and affective dimension is more frequent and has a longer tradition (for a review see Upadyaya \& Salmela-Aro, 2013). As these two different approaches to engagement coexist, research findings are sometimes difficult to apprehend.

Studies using the European framework have found significant relationships among university students' engagement, academic success (e.g., Schaufeli, Martinez, et al., 2002) and well-being (Choi, 2013). In the cross-national study by Schaufeli, Martinez, et al. (2002) and Schaufeli, Salanova, et al. (2002), university students' dedication was only correlated with academic achievement in the Spanish sample, but the relationship was weak; vigour was the only engagement dimension that was correlated with academic achievement across all three countries. Choi (2013) found that dedication was a predictor of undergraduate students' well-being, but vigour was not.

Studies with adolescent pupils have also found an association among high levels of school engagement, higher academic performance and levels of well-being (Chase, Hilliard, Geldhof, Warren, \& Lerner, 2014; Lewis, Huebner, Malone, \& Valois, 2011; Li \& Lerner, 2011; Salmela-Aro \& Upadyaya, 2012; Wang et al., 2015; Willingham, Pollack, \& Lewis, 2002). Longitudinal studies have also shown that engaged students in secondary school were more likely to obtain better academic outcomes in the long term, such as finishing university degrees (Tuominen-Soini \& Salmela-Aro, 2014). However, most of these studies have used the North American approach towards engagement.

The relationship among school burnout, engagement, academic achievement and well-being can be understood within the frameworks of the person-environment fit and the demands-resource models. According to the person-environment fit theory, "an individual's behaviour is jointly determined by characteristics of the person and properties of the immediate environment" (Eccles \& Midgley, 1989, p. 174). As a consequence, a mismatch between the students' developmental needs and the school environment can lead to a decrease in motivation, and to poor adjustment and mental health outcomes (Symonds, Dietrich, Chow, \& Salmela-Aro, 2016). The basic premise of the demands-resources model is that the environment can not only provide resources, but also impose demands on students: demands involve effort and usually have physical and/or psychological costs, whereas the resources can help to diminish the stress induced by this effort and aid the individuals in fulfilling their personal needs and boost their positive adjustment (Demerouti, Bakker, Nachreiner, \& Schaufeli, 2001; 
Schaufeli \& Bakker, 2004). Burnout is fostered when the school environment imposes a high level of demands and offers few study resources. On the opposite, the availability of study resources and personal resources such as high self-efficacy, fosters engagement with the school tasks and leads to more positive outcomes (Salmela-Aro \& Upadyaya, 2014b). Results from longitudinal studies with secondary school students also indicated that engagement increased when these perceived the school tasks as challenging, but at the same time perceived some degree of control of the learning environment, considered having adequate skills to face the demands and perceived high instruction quality (Gemici \& Lu, 2014; Shernoff, Csikszentmihalyi, Schneider, \& Shernoff, 2014).

\section{Gender differences}

With regards to pupils' educational attainment, a gender gap has been consistently recorded pointing to male pupils' being at a disadvantage when compared to females, both at university (e.g., Robbins et al., 2004) and secondary school (e.g., McPhee, Marks, \& Marks, 2013) levels.

There is a far less clear picture in terms of gender differences in positive well-being, given the existing diversity of concepts and measures under this heading. Some research studies on youths, have indicated that females have a higher tendency to report happiness and life satisfaction, other studies have reported higher scores in positive well-being measures for males, while in other studies no gender differences have been found (Lucas \& Gohm, 2000; Rees, Pople, \& Goswami, 2011). Data from longitudinal research also suggested that life satisfaction increased in both genders across the transition to and during secondary school but more variability in the trajectories of girls was found (Salmela-Aro \& Tuominen-Soini, 2010).

In general, literature on gender differences in students' burnout has also produced inconsistent findings. Some studies have reported no male-female differences in university students' burnout (e.g., Backović, Živojinović, Maksimović, \& Maksimović, 2012; Dahlin \& Runeson, 2007), whereas other studies have indicated significant gender differences (e.g., Martínez, Marques Pinto, \& Lopes da Silva, 2001; Weckwerth \& Flynn, 2006). As far as secondary school pupils are concerned, the results of research appear to be more consistent, with girls obtaining higher levels of burnout than boys (for a review see Walburg, 2014). Results from longitudinal studies with Finnish students suggested that burnout increases in both genders when students enter an academic track in secondary school, but boys seem prone to a higher increase in overall burnout, and particularly in cynicism, during this period (Salmela-Aro \& Tynkkynen, 2012; Salmela-Aro, Kiuru, \& Nurmi, 2008).

Our review of the North American approach to school engagement literature found a similar (and related) gender pattern to that identified in educational attainment, with girls scoring higher in different measures of engagement (e.g., Gemici \& Lu, 2014; Harper, 2004; Kinzie et al., 2007; McPhee et al., 2013). Studies using the European approach seem to mirror the same findings (e.g., Salmela-Aro \& Upadyaya, 2012).

\section{The present study}

Overall, research results demonstrate a negative relationship between burnout and well-being and a positive relationship between engagement and well-being. The same pattern of relationships has been obtained for academic achievement. Although these relations have been profusely studied in adult, worker and university student samples, data on secondary school pupils are not so abundant. Moreover, most of the research on the effects of adolescents' school engagement on wellbeing and academic success has used the North American approach and not the European approach (see, for example, the reviews by Upadyaya \& Salmela-Aro, 2013; Wang \& Degol, 2014). Thus, more research following the latter approach is needed, especially in secondary school pupils. Moreover, the diversity of demands of different educational systems may exert some influence on the burnout and engagement levels of secondary school pupils and in the relationships between these two variables and the pupils' academic achievement and well-being. Therefore, further research is required in different countries.

The main aim of our investigation was to examine the relations among the core burnout and engagement dimensions, wellbeing, and academic performance in Portuguese pupils who attended regular secondary school courses (academic track).

The study hypotheses were as follows:

H1: Burnout and engagement scales are negatively correlated, particularly exhaustion and vigour, as well as cynicism and dedication;

H2: Higher levels of exhaustion and cynicism are associated with lower levels of well-being;

H3: Higher levels of exhaustion and cynicism are associated with lower academic achievement;

H4: Higher levels of vigour and dedication are associated with higher levels of well-being;

H5: Higher levels of vigour and dedication are associated with higher academic achievement.

The model which was tested to investigate these hypotheses is depicted in Fig. 1. Given the unclear scenario of the relationships between gender and the studied variables we also tested whether the model was invariant across girls and boys.

\section{Method}

\section{Participants}

The sample of this study was composed of 489 pupils from two Portuguese state secondary schools located in Braga $(\mathrm{n}=225 ; 46 \%)$ and in Lisbon $(\mathrm{n}=264 ; 54 \%)$. The sample had a mean age of 16.31 years (SD $=1.11)$, ranging from 13 to 20 


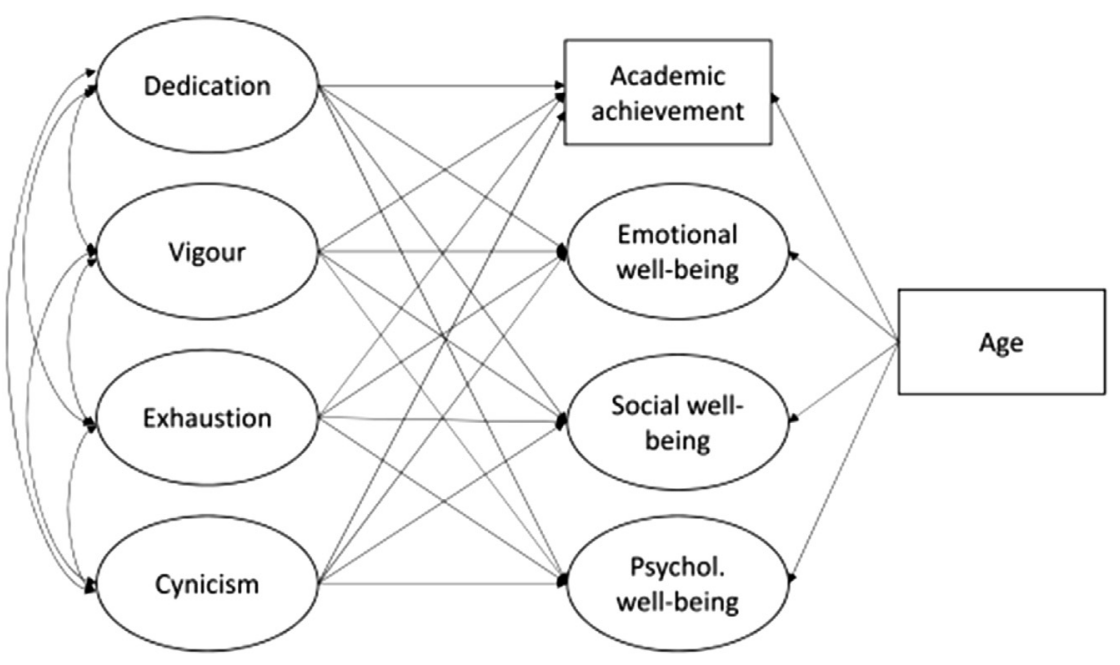

Fig. 1. Tested model to investigate the predictive power of burnout and engagement on the well-being and academic achievement of secondary school pupils.

years of age, and $54.6 \%(n=267)$ of the participants were girls. All pupils attended regular secondary school courses, i.e. nonvocational. Table 1 presents the distribution of the sample by gender, level attended and study areas. The pupils were distributed equally by study areas and levels and the mean age of boys and girls was similar $\left(\mathrm{t}_{(481)}=1.309, \mathrm{p}=.191\right)$. No association between gender and level was found $\left(\chi_{(2)}^{2}=.936, \mathrm{p}=.626\right)$, however higher enrolment of girls in Languages and Humanities and Arts courses was observed than of boys $\left(\chi_{(3)}^{2}=38.923, \mathrm{p}<.001\right)$.

\section{Instruments}

The Maslach Burnout Inventory - Student Survey (MBI-SS; Schaufeli, Martinez, et al., 2002) is a self-report measure, in which pupils have to respond to how often they felt a set of feelings in the school context, using a seven-point Likert scale $(0=$ Never/Anytime; 6 = Always/Everyday). In this study, only the items that compose the exhaustion (feelings of overwhelmingness, detrition of personal resources, and lack of energy; 5 items) and the cynicism (behaviours and feelings of detachment from school activities and related issues; 4 items) subscales were used. The Portuguese adaptation of the MBI-SS for secondary school pupils (Marques Pinto, 2013) obtained adequate internal consistency values (Exhaustion: $\alpha=.72$; Cynicism: $\alpha=.72$ ).

The Utrecht Work Engagement Scale - Students (UWES-S; Schaufeli, Martinez, et al., 2002) is a self-report measure for students, in which they have to respond to how often they experience a set of feelings, beliefs or behaviours, using a sevenpoint Likert scale $(0=$ Never; 6 = Always). In this study, only the items that compose the vigour (behaviours of persistence, efforts to persist and a mental state of vitality; 6 items) and dedication (feelings of pride and meaning towards one's assignment; 5 items) subscales were used. The adaptation for the Portuguese population obtained good psychometric properties, both in university students (Schaufeli, Martinez, et al., 2002) and secondary school pupils (Cadime, Lima, Marques Pinto, \& Ribeiro, 2016). Cronbach's alpha and composite reliability (CR) indicators were high in the secondary school sample (Vigour: $\alpha=.84, \mathrm{CR}=.87$; Dedication: $\alpha=.84, \mathrm{CR}=.88$ ).

Table 1

Sample distribution by gender, level, area of study and age.

\begin{tabular}{|c|c|c|c|c|}
\hline Variables & Boys, n (\%) & Girls, n (\%) & $\mathrm{N} / \mathrm{I}$ gender, $\mathrm{n}(\%)$ & Total, n (\%) \\
\hline \multicolumn{5}{|l|}{ Levels } \\
\hline 10th & $78(35.3 \%)$ & $106(39.7 \%)$ & 0 & $184(37.6 \%)$ \\
\hline 11th & 67 (30.3\%) & 75 (28.1\%) & 0 & $143(29.2 \%)$ \\
\hline 12th & 75 (33.9\%) & $86(32.2 \%)$ & 1 & $161(32.9 \%)$ \\
\hline $\mathrm{N} / \mathrm{I}$ & $1(0.5 \%)$ & 0 & 0 & 0 \\
\hline \multicolumn{5}{|l|}{ Area of study } \\
\hline Science and Technology & $55(24.9 \%)$ & $51(19.1 \%)$ & 1 & $107(21.9 \%)$ \\
\hline Socio-economic Sciences & $91(41.2 \%)$ & $53(19.9 \%)$ & 0 & $144(29.4 \%)$ \\
\hline Languages and Humanities & $37(16.7 \%)$ & 75 (28.1\%) & 0 & $112(22.9 \%)$ \\
\hline Arts & 38 (17.2\%) & $88(33 \%)$ & 0 & $126(25.8 \%)$ \\
\hline Mean age (SD) & $16.38(1.14)$ & $16.25(1.09)$ & - & $16.31(1.11)$ \\
\hline
\end{tabular}

Note: $\mathrm{N} / \mathrm{I}=$ No information; SD-Standard deviation. 
The Mental Health Continuum-Short Form-for youths (MHC-SF; Keyes, 2009) is a self-report measure composed of 14 items that measures the levels of subjective well-being. Participants have to respond to how frequently, in the last month, they have felt in a certain way, using a six-point Likert scale $(0=$ Never; $5=$ Everyday $)$. In the MHC-SF subjective well-being encompasses three factors: emotional well-being (positive emotions; assessed by the degree of happiness, life satisfaction and interest), social well-being (symptoms of positive social functioning; assessed by the degree of social contribution, integration and acceptance), and psychological well-being (symptoms of positive psychological functioning; assessed by the degree of self-acceptance, personal growth and autonomy). The Portuguese version of the MHC-SF, studied with secondary school pupils (Matos et al., 2010), included three factors showing high internal consistency: emotional ( $\alpha=.85 ; 5$ items), social ( $\alpha=.80 ; 5$ items), and psychological ( $\alpha=.83 ; 4$ items) well-being.

Academic achievement was measured by taking the mean of the classifications (measured on a 1-20 scale) achieved in the first semester and reported by each pupil.

\section{Procedures}

The data collection was made by Psychology master students who administered the questionnaires in the classrooms, during class time, with no time restrictions. Data collection required authorization from the Portuguese Ministry of Education and the respective school boards. Pupils and parents were also requested to provide their informed consent in writing. The questionnaires did not request the name or other identifying variables, to ensure the anonymity of data.

\section{Analysis strategy}

Descriptive statistics and independent sample t-tests were conducted to test for differences between boys and girls, using the IBM $^{\circledR}$ SPSS ${ }^{\circledR}$ Statistics 22. Pearson's correlations were also computed. Then, multi-group structural equation modelling (SEM) was conducted using Mplus, version 6.1 (Muthén \& Muthén, 2012). Scores in the corresponding items, for all variables, with the exception of academic achievement, which was an observed variable, were used as indicators of the latent variables. These analyses were conducted in two steps. The first step was to examine the measurement invariance of the burnout, engagement and well-being measures, in order to analyse the equivalence of the factor loadings and intercepts across both genders. For each measure, we first tested a model where loadings and intercepts were allowed to vary across groups (configural model). These models served as baseline models for comparison purposes. We then tested a model for each measure, where loadings and intercepts were constrained to be equal between boys and girls (scalar invariance model).

In the second step, the invariance of the structural model was analysed using the following approach: (a) a fully constrained model, where all regression paths were constrained to be equal across boys and girls was tested; (b) the constrained model was compared against a series of models where regression paths were allowed to vary between gender groups. Due to the high age range, age effects were also controlled in the model (see Fig. 1).

In order to assess model fit, the chi-square $\left(\chi^{2}\right)$ value, the ratio $\chi^{2} / \mathrm{df}$, the Comparative Fit Index (CFI), the Root Mean Square Error of Approximation (RMSEA) and the Standardized Root Mean Square Residual (SRMR) were considered. Values for the ratio $\chi^{2} / \mathrm{df}$ below 3.00 are generally considered indicators of an acceptable fit and below 2.00 indicators of a good model fit (Bollen, 1989). Model fit is also considered acceptable when CFI values are above .90 (Hoyle \& Panter, 1995), RMSEA below.08 (Browne \& Cudeck, 1993) and SRMR below .10 (Schermelleh-Engel, Moosbrugger, \& Müller, 2003). Chi-square difference test and the model comparison indices Akaike Information Criterion (AIC) and Bayesian Information Criterion (BIC) were used to evaluate the invariance of the model in both steps of the multi-group analyses. The maximum likelihood estimator was used. Seventy five cases had at least one missing value. Little's (1988) MCAR test was non-significant, $\chi^{2}(2264)=2360.49, p=.08$, indicating that the pattern of missingness was completely random. Full information maximum likelihood (FIML) was used to account for missing data. The significance level was $5 \%$ for all analyses.

\section{Results}

Descriptive analyses, gender differences and relationship between variables

Table 2 presents the descriptive statistics and the tests of differences by gender. Results indicated that boys had significantly higher levels of social and psychological well-being and girls had significantly higher levels of vigour. Therefore, subsequent analyses were conducted separately for each group.

Table 3 presents the correlation matrix for pupils' academic achievement, well-being, burnout and engagement for girls and boys. Academic achievement was not significantly correlated with any of the well-being dimensions in either of the groups. However, academic achievement had significant but low correlations with cynicism and with the two engagement dimensions, indicating that higher levels of academic achievement were associated with lower levels of cynicism, and higher levels of vigour and dedication. Academic achievement was correlated with exhaustion in boys, but not in girls.

Low-to-medium correlations were obtained among all the well-being dimensions, the burnout and engagement dimensions in girls. In boys, psychological well-being was not correlated with the burnout dimensions. As expected, well-being was negatively correlated with the two burnout dimensions and positively correlated with the engagement dimensions. 
Table 2

Descriptive statistics and differential tests for boys and girls.

\begin{tabular}{|c|c|c|c|c|c|c|c|c|c|}
\hline \multirow[t]{2}{*}{ Variables } & \multicolumn{3}{|c|}{ Full sample } & \multicolumn{2}{|l|}{ Boys } & \multicolumn{2}{|l|}{ Girls } & \multirow[t]{2}{*}{$\mathrm{t}$} & \multirow[t]{2}{*}{$\mathrm{p}$} \\
\hline & $\mathrm{N}$ & Mean & SD & Mean & SD & Mean & SD & & \\
\hline Academic achievement & 377 & 12.82 & 2.41 & 12.56 & 2.50 & 13.02 & 2.33 & -1.85 & .07 \\
\hline Emotional well-being & 475 & 21.92 & 5.29 & 22.31 & 5.06 & 21.61 & 5.45 & 1.43 & .15 \\
\hline Social well-being & 483 & 16.78 & 5.59 & 17.36 & 5.68 & 16.30 & 5.48 & 2.08 & .04 \\
\hline Psychological well-being & 483 & 17.35 & 4.54 & 17.84 & 4.44 & 16.95 & 4.60 & 2.15 & .03 \\
\hline Exhaustion & 472 & 18.73 & 6.09 & 18.38 & 6.31 & 19.01 & 5.91 & -1.12 & .26 \\
\hline Cynicism & 468 & 10.88 & 5.32 & 11.08 & 5.47 & 10.70 & 5.18 & 0.78 & .44 \\
\hline Vigour & 473 & 20.02 & 7.19 & 19.09 & 7.40 & 20.78 & 6.94 & -2.56 & .01 \\
\hline Dedication & 476 & 21.85 & 6.28 & 21.65 & 6.33 & 22.01 & 6.24 & -0.61 & .54 \\
\hline
\end{tabular}

Note: SD-Standard deviation.

Table 3

Correlations among well-being, burnout, school engagement and academic achievement for boys and girls.

\begin{tabular}{|c|c|c|c|c|c|c|c|c|c|}
\hline Variables & 1. & 2. & 3. & 4. & 5. & 6. & 7. & 8. & 9. \\
\hline 1. Academic achievement & - & -.151 & -.070 & -.036 & $-.273^{* *}$ & $-.344^{* * *}$ & $.252^{* *}$ & $.175^{*}$ & -.154 \\
\hline 2. Emotional well-being & .019 & - & $.613^{* * *}$ & $.649^{* * *}$ & $-.196^{* *}$ & $-.182^{* *}$ & $.367^{* * *}$ & $.422^{* * *}$ & -.110 \\
\hline 3. Social well-being & -.097 & $.721^{* * *}$ & - & $.513^{* * *}$ & $-.177^{* *}$ & $-.174^{*}$ & $.343^{* * *}$ & $.412^{* * *}$ & -.102 \\
\hline 4. Psychological well-being & -.011 & $.710^{* * *}$ & $.624^{* * *}$ & - & -.108 & -.119 & $.263^{* * *}$ & $.389^{* * *}$ & -.070 \\
\hline 5. Exhaustion & -.046 & $-.321^{* * *}$ & $-.234^{* * *}$ & $-.244^{* * *}$ & - & $.658^{* * *}$ & $-.279^{* * *}$ & $-.194^{* *}$ & -.003 \\
\hline 6. Cynicism & $-.181^{*}$ & $-.348^{* * *}$ & $-.191^{* *}$ & $-.293^{* * *}$ & $.531^{* * *}$ & - & $-.232^{* *}$ & $-.326^{* * *}$ & .046 \\
\hline 7. Vigour & $.251^{* * * *}$ & $.556^{* * *}$ & $.439^{* * *}$ & $.341^{* * *}$ & $-.285^{* * *}$ & $-.319^{* * *}$ & - & $.573^{* * *}$ & -.070 \\
\hline 8. Dedication & $.169^{*}$ & $.564^{* * *}$ & $.435^{* * *}$ & $.436^{* * *}$ & $-.230^{* * *}$ & $-.416^{* * *}$ & $.706^{* * *}$ & - & $-.142 *$ \\
\hline 9. Age & -.123 & .007 & -.051 & .021 & $-.124^{*}$ & $.141^{*}$ & -.070 & $-.136^{*}$ & - \\
\hline
\end{tabular}

Note: Coefficients below diagonal are for girls; above diagonal are for boys.

${ }^{* * *} \mathrm{p}<.001 ;{ }^{* *} \mathrm{p}<.01 ;{ }^{*} \mathrm{p}<.05$.

Regarding the relationship between the burnout and engagement dimensions, exhaustion revealed negative and low-tomedium correlations with vigour and dedication, which were very similar across all three variables. Cynicism was also negatively and moderately correlated with the engagement dimensions. Age was negatively correlated with dedication both in boys and girls and with exhaustion, but only in girls. Age and cynicism were positively correlated in girls, albeit these correlations were low.

\section{Multi-group analyses}

\section{Measurement models}

Table 4 presents the model fit results for the measurement invariance testing. The model fit of the measurement models was not adequate in any of the three measures. Inspection of the modification indices indicated that allowing the correlation of residuals improved the model fit in both groups. The models were then re-run, allowing only the correlation of residuals of items belonging to the same subscale (see Table 4).

The configural models that included the residuals' correlations presented an adequate fit. The models where the factor loadings and intercepts were constrained to be equal across boys and girls (scalar), also presented an adequate fit. Moreover, the chi-square difference tests indicated that there were no differences between the configural and the scalar invariance model for UWES-S, $\Delta \chi^{2}(22)=27.30, \mathrm{p}=.20$. However, the differences were significant in the measurement models for MBISS, $\Delta \chi^{2}(18)=32.42, \mathrm{p}=.02$, and MHC-SF $\Delta \chi^{2}(28)=66.85, \mathrm{p}<.001$. The modification indices flagged one intercept in the MBI-SS measurement model and one loading and three intercepts in the MHC-SF measurement model as non-invariant. Therefore, partial invariance models were tested, where these parameters were freely estimated for each group. The chisquare difference tests indicated that the partial invariance and the configural models fit equally well, both for MBI-SS, $\Delta \chi^{2}(17)=26.70, \mathrm{p}=.06$, and for MHC-SF, $\Delta \chi^{2}(24)=34.01, \mathrm{p}=.08$. Moreover, these partial measurement models displayed the lowest AIC and BIC when compared with all previous models. Therefore, the fully constrained measurement model for UWES-S, and the partially constrained measurement models for MBI-SS and MHC-SF were used in the full structural model, given that these are more parsimonious.

\section{Structural model}

The fit of the model where all path coefficients were constrained to be equal between gender groups displayed an acceptable fit, $\chi^{2}(1185)=2091.39, \mathrm{p}<.001 ; \chi^{2} / \mathrm{df}=1.76 ;$ CFI $=.89 ;$ RMSEA $=.06,90 \%$ CI $[.05-.06]$; SRMR $=.07$; $\mathrm{AIC}=55,127.56$; $\mathrm{BIC}=56,026.26$. Observation of the Lagrange multiplier tests did not indicate that the removal of any equality constraint in the regression paths would lead to an improvement of the model fit. The fit of the model where all regression paths were not constrained to be equal across boys and girls was acceptable, $\chi^{2}(1165)=2073.79$, 
Table 4

Measurement invariance of the engagement, burnout and well-being measures between girls and boys.

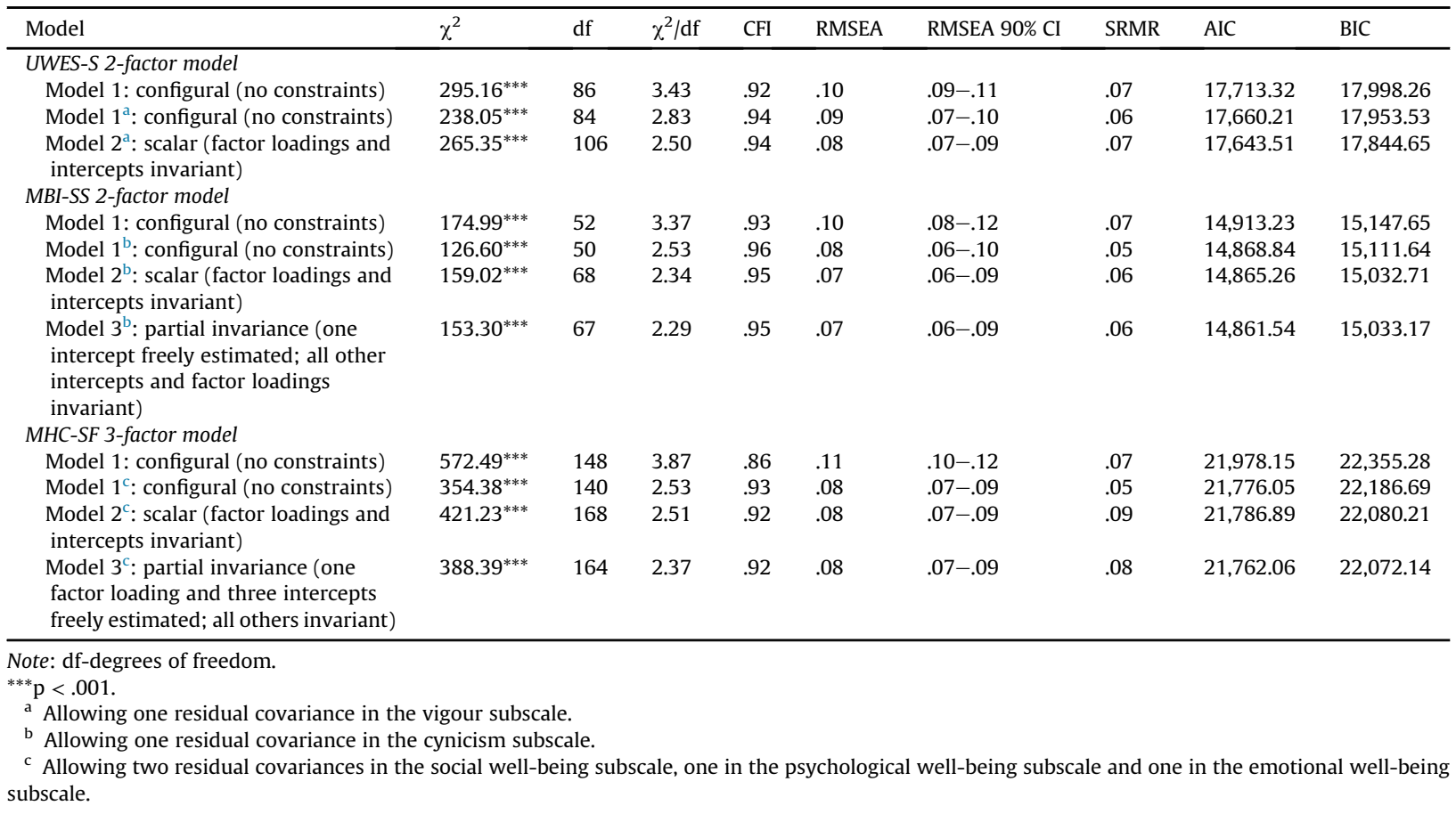

$\mathrm{p}<.001 ; \chi^{2} / \mathrm{df}=1.78 ; \mathrm{CFI}=.89 ; \mathrm{RMSEA}=.06,90 \% \mathrm{CI}[.05-.06] ;$ SRMR $=.07 ;$ AIC $=55,149.96$; BIC $=56,132.26$, however the chi-square difference tests indicated that this model did not fit better than the fully constrained model, $\Delta \chi^{2}(20)=17.60$, $\mathrm{p}=.61$. Fig. 2 depicts the results for the constrained structural model. The model explained $12.2 \%$ of the variance in academic achievement, $40.4 \%$ of the variance in emotional well-being, $36.1 \%$ of the variance in social well-being and $27.1 \%$ of the variance in psychological well-being in boys. As for girls, the model explained $15.2 \%$ of the variance in academic achievement, $39.3 \%$ of the variance in emotional well-being, $37.7 \%$ of the variance in social well-being and $29.2 \%$ of the variance in psychological well-being.

Regarding the burnout dimensions, exhaustion did not predict any well-being dimension or academic achievement. Cynicism significantly predicted academic achievement, with lower levels of cynicism predicting higher academic achievement, but not well-being.

Regarding the engagement dimensions, dedication predicted all well-being dimensions, indicating that secondary school pupils with higher levels of dedication towards their studies had higher levels of emotional, social and psychological wellbeing. Vigour predicted not only emotional and social well-being but also academic achievement.

\section{Discussion and conclusions}

This study aimed to investigate the relationships among burnout, engagement, academic achievement and emotional, social and psychological well-being in Portuguese secondary school pupils. A further goal was to explore whether there were gender differences in these relationships.

The first hypothesis of the study was supported by our results: mirroring previous results (Schaufeli, Martinez, et al., 2002; Schaufeli, Salanova, et al., 2002), our results indicated that, as predicted, the two burnout dimensions were negatively correlated with the two engagement dimensions. However, the correlation between exhaustion and vigour was not particularly high, a result already observed in previous studies with university students (Schaufeli, Martinez, et al., 2002; Schaufeli, Salanova, et al., 2002). Cynicism and dedication had slightly higher correlations than exhaustion and vigour, however these were weaker than those previously observed for university students (Schaufeli, Martinez, et al., 2002). All these results were very similar for boys and girls.

The second hypothesis, which stated that higher levels of exhaustion and cynicism are associated with lower levels of well-being, was only partially supported by the results of this study. Low correlations between these variables were observed but the results from SEM indicated that none of the two burnout dimensions was uniquely related with the adolescents' wellbeing, regardless of their gender. Regarding cynicism, it is possible that, as stated in other studies, students with high scores in this dimension are "psychologically detached from school and that their well-being is more influenced by experiences other than school-related ones" (Tuominen-Soini \& Salmela-Aro, 2014, p. 659). The reasons behind the result regarding exhaustion are unclear, but some clues can be found in studies that adopted a person-centered approach. For example, the study by 


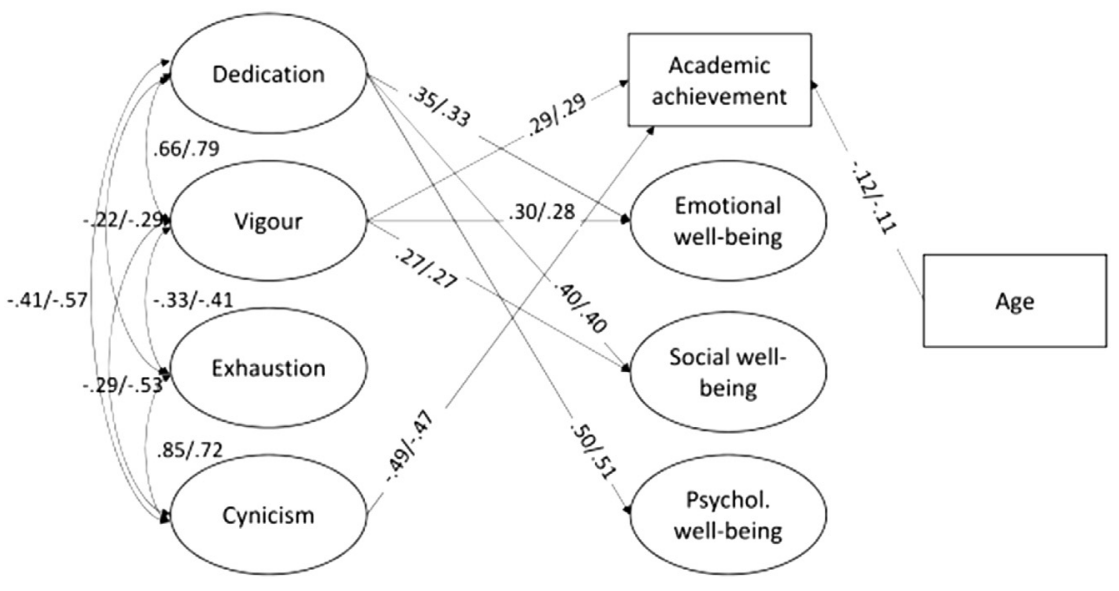

Fig. 2. Standardized coefficients of the structural model for the relationships among engagement, burnout, well-being and academic achievement. The estimates that appear first refer to the boys' group and the estimates appearing in second place refer to the girls' group. Note: Only significant path coefficients $(\mathrm{p}<.05)$ are shown. Measured indicators, error terms and residual covariances were also omitted to improve clarity.

Tuominen-Soini and Salmela-Aro (2014) explored the existence of burnout and engagement profiles in secondary school students and found that engaged-exhausted students were particularly prone to psychological distress. Therefore, it is possible that exhaustion does not affect well-being equally in all students but has negative effects mainly in students oriented to high performance that are engaged with the school work but that are at the same time suffering an erosion process due to the heavy study demands.

Moreover, no gender differences were found for exhaustion and cynicism, although almost all of the studies conducted with secondary school pupils in other countries found that girls usually have higher school-related burnout scores (Walburg, 2014). Our results appear to be more similar to those obtained in previous studies conducted with university student samples which found no gender differences in burnout levels (Backović et al., 2012; Dahlin \& Runeson, 2007). This finding suggests that gender differences in the school-related burnout of adolescents are not universal and may depend on other personal variables, such as the coping strategies used by each gender (Yusoff, 2010), or on environmental variables, such as the demands of each educational system.

The third hypothesis, which stated that higher levels of exhaustion and cynicism are associated with lower academic achievement, was partially supported. As predicted, cynicism was negatively correlated with academic achievement in boys and girls, but exhaustion was only correlated with achievement in boys and yet the relationship was weak. Low or nonexistent correlations between burnout dimensions and academic achievement had already been observed for university (Schaufeli, Martinez, et al., 2002) and secondary school samples (Wang et al., 2015). When considering the SEM results, exhaustion was not uniquely related with academic achievement. Having only exhaustion symptoms is not sufficient for a burnout diagnosis (Maslach et al., 2001), but indicates that the student is facing stressful situations during a considerable period of time, which leads to feelings of lack of vitality and low levels of energy. However, the experiences of stress can be accompanied by adaptive coping strategies that protect the students against negative outcomes, allowing them to maintain their academic achievement. On the contrary, SEM results suggest that when the student becomes cynic and has a detached attitude towards studies and school activities, his academic achievement decreases, indicating that cynicism may be acting as a defensive and dysfunctional coping strategy (Maslach et al., 2001). Students high in cynicism have lost their enthusiasm and became sceptical towards their studies. This scepticism and the negative emotions associated probably narrow their cognitive focus (Fredrickson, 2001) when facing learning tasks and close their mind (Leiter, 2012), thus damaging their academic achievement.

The results of this study also provided support for the fourth hypothesis, given that medium-sized positive correlations were found among the engagement and the well-being dimensions in both genders. Moreover, results from SEM indicated that dedication was a significant predictor of all three well-being dimensions, and vigour was a predictor of emotional and social well-being. This result suggests that vigorous and dedicated students who are energetic and immersed in their studies are more successful in preserving their personal well-being (Keyes, 2009): students with high psychological well-being perceive themselves as progressing in their personal lives and life goals, which in turn contributes to their self-acceptance and to their inter-personal relations; students with high levels of social well-being perceive progression in their school community, and consequently in their relationship with society at large; and students with higher subjective well-being have more positive feelings and life satisfaction. The main role of dedication as the central dimension predicting well-being had already been found in the study by Choi (2013) with college pupils, but the results of our study indicate that vigour is also a significant predictor of positive emotions and of feelings of social contribution, integration and acceptance.

Although the previous studies conducted in other countries found gender-related differences in school engagement, not only in university students (Harper, 2004; Kinzie et al., 2007; McPhee et al., 2013), but also in secondary-school pupils 
(Salmela-Aro \& Upadyaya, 2012), in our study gender differences were observed for vigour, but not for dedication. This result suggests that, similarly to what happens with burnout, these differences are not universal and may be influenced by cultural aspects, by the demands of the educational system in different countries, or even by a combination of both.

The fifth hypothesis of this study - higher levels of vigour and dedication are associated with higher academic achievement-was partially supported. Low correlations between the engagement dimensions and academic achievement were found, a result that had already been found for university students in studies using the same engagement approach (e.g., Schaufeli, Martinez, et al., 2002) and in studies with secondary school pupils (Chase et al., 2014; Li \& Lerner, 2011; Wang et al., 2015; Willingham et al., 2002). However, considering SEM results, only vigour was uniquely related to academic achievement. If we recall the definition of vigour - "high levels of energy and mental resilience while working and by the willingness and ability to invest effort in one's work" (Schaufeli et al., 2002, p. 465)—, the mechanism underlying this relationship seems evident: secondary school pupils with higher levels of vigour feel more vitality and are more persistent in adverse situations, direct and maintain effort in their academic work and consequently achieve higher academic achievement. This finding can also be partially related with the characteristics of the Portuguese educational system, where the number of university admissions is limited and the entry of applicants depends on a score that is calculated for each student on the basis of the average secondary school mark which takes the afore-mentioned specialized area of three years into consideration, plus the marks obtained in National Exams. Consequently, secondary school pupils face severe demands and are frequently confronted with an extreme pressure to succeed and obtain high academic scores. In such a context, the ability to maintain high levels of energy and resilience appears to be crucial to succeed in terms of academic achievement.

Overall, the results obtained in the multi-group analyses suggest that the magnitude of the relationships among the variables are similar for boys and girls, indicating that neither of the groups appears to be more vulnerable than the other to the effects of burnout or engagement.

One of the main limitations of this study is related to the lack of private school pupils and those following a non-academic path (i.e., vocational education) in the sample. Given the different demands of academic and non-academic tracks in secondary school (Salmela-Aro \& Tynkkynen, 2012), future studies should compare whether relationships between the dimensions of engagement and burnout and wellbeing and academic achievement are similar across both groups. It may also be the case that other contextual and personal variables (e.g., parental involvement or positive affect; Awang-Hashim, Kaur, \& Noman, 2015; Moreira, Dias, Vaz, \& Vaz, 2013) that were not considered in this study are moderators of the relationships tested in this study. Another limitation is that a cross-sectional design was used and, therefore, no developmental relationships among the variables were studied.

The choice of the burnout and engagement measures used in this study was based on two criteria: (a) to be adapted and have shown previously robust psychometric properties for the targeted population (Portuguese adolescents) in past studies; (b) to enable a comparison with the results obtained for older Portuguese students (university level). Therefore, the versions for students of the inventories originally developed to be used with workers were chosen. However, in other countries, research with secondary school pupils has used measures specifically developed to assess school-related burnout and engagement (e.g., SBI and EDA, Salmela-Aro, Kiuru, et al., 2009; Salmela-Aro \& Upadyaya, 2012). Future research should investigate if the choice of measures has any bearing on the results obtained regarding the studied relations.

Despite these limitations, this study provides an important contribution to the study of the relationships among burnout, engagement, well-being and academic achievement in Portuguese secondary school pupils within an academic track: a cynical and detached attitude towards school and the feelings of vigour are the main predictors of academic achievement, whereas well-being is predicted by the school engagement dimensions but not by the burnout dimensions. Taken together, these findings highlight the importance of promoting engagement if the goal is to improve well-being, but also of decreasing burnout levels if the goal is to improve academic achievement.

\section{Acknowledgments}

This study was partially conducted at Psychology Research Centre (UID/PSI/01662/2013), University of Minho, and supported by the Portuguese Foundation for Science and Technology and the Portuguese Ministry of Science, Technology and Higher Education, through national funds, and co-financed by FEDER, through COMPETE2020, under the PT2020 Partnership Agreement (POCI-01-0145-FEDER-007653). The first author is also supported by grant SFRH/BPD/102549/2014 from the Portuguese Foundation for Science and Technology.

\section{References}

American Psychological Association. (2014). Stress in America survey. Washington, DC: APA.

Awang-Hashim, R., Kaur, A., \& Noman, M. (2015). The interplay of socio-psychological factors on school engagement among early adolescents. Journal of Adolescence, 45, 214-224. http://dx.doi.org/10.1016/j.adolescence.2015.10.001.

Backović, D. V., Živojinović, J. I., Maksimović, J., \& Maksimović, M. (2012). Gender differences in academic stress and burnout among medical students in final years of education. Psychiatria Danubina, 24(2), 175-181.

Bollen, K. A. (1989). Structural equation models with latent variables. New York: Wiley.

Browne, M. W., \& Cudeck, R. (1993). Alternative ways of assessing model fit. In K. A. Bollen, \& J. S. Long (Eds.), Testing structural equation models (pp. 136-162). Beverly Hills, CA: Sage. Book Section. 
Cadime, I., Lima, S., Marques Pinto, A., \& Ribeiro, I. (2016). Measurement invariance of the Utrecht Work Engagement Scale for Students: a study across secondary school pupils and university students. European Journal of Developmental Psychology, 13(2), 254-263. http://dx.doi.org/10.1080/17405629. 2016.1148595.

Chase, P., Hilliard, L., Geldhof, G. J., Warren, D., \& Lerner, R. (2014). Academic achievement in the high school years: The changing role of school engagement. Journal of Youth \& Adolescence, 43(6), 884-896. http://dx.doi.org/10.1007/s10964-013-0085-4.

Choi, J. (2013). The independence of burnout and engagement: Incremental predictive validity and construct reappraisal as different combinations of the same components (energy and evaluation). University of Western Ontario.

Compas, B. E., Orosan, P. G., \& Grant, K. E. (1993). Adolescent stress and coping: Implications for psychopathology during adolescence. Journal of Adolescence, 16, 331-349.

Dahlin, M., Joneborg, N., \& Runeson, B. (2007). Performance-based self-esteem and burnout in a cross-sectional study of medical students. Medical Teacher, 29(1), 43-48. http://dx.doi.org/10.1080/01421590601175309.

Dahlin, M., \& Runeson, B. (2007). Burnout and psychiatric morbidity among medical students entering clinical training: A three year prospective questionnaire and interview-based study. BMC Medical Education, 7, 6. http://dx.doi.org/10.1186/1472-6920-7-6.

Demerouti, E., Bakker, A. B., Nachreiner, F., \& Schaufeli, W. (2001). The job demands-resources model of burnout. Journal of Applied Psychology, 86(3), 499-512.

Eccles, J. S., \& Midgley, C. (1989). Stage-environment fit: Developmentally appropriate classrooms for young adolescents. In C. Ames, \& R. Ames (Eds.), Research on motivation in education: Goals and cognitions (pp. 139-186). San Diego, California: Academic Press, Inc.

Fredrickson, B. L. (2001). The role of positive emotions in positive psychology: The broaden-and-build theory of positive emotions. The American Psychologist, 56(3), 218-226.

Gemici, S., \& Lu, T. (2014). Do schools influence student engagement in the high school years? Longitudinal Surveys of Australian Youth - Research Reports, 69, $1-46$.

Green, D., Walkey, F., \& Taylor, A. (1991). The three-factor structure of the Maslach burnout inventory: A multicultural, multinational confirmatory study Journal of Social Behavior and Personality, 6, 453-472.

Harper, S. R. (2004). Gender differences in student engagement among African American undergraduates at historically Black Colleges and Universities Journal of College Student Development, 45(3), 271-284.

Hoyle, R. H., \& Panter, A. T. (1995). Writing about structural equation models. In R. H. Hoyle (Ed.), Structural equational modeling: Concepts, issues, and applications (pp. 158-176). Thousand Oaks, CA: Sage Publications. Book Section.

Keyes, C. L. M. (2009). Brief description of the Mental Health Continuum Short Form (MHC-SF). Retrieved from https://www.aacu.org/sites/default/files/MHCSFEnglish.pdf.

Kinzie, J., Gonyea, R., Kuh, G. D., Umbach, P., Wabash, C. B., \& Korkmaz, A. (2007). The relationship between gender and student engagement in college. Retrieved from http://cpr.indiana.edu/uploads/Gender\%20and\%20Student\%20Engagement\%20in\%20College\%20ASHE\%202007\%.

Leiter, M. P. (2012). Wellbeing \& burnout (Invited workshop). Worklab 2012. Helsinki, Finland: European Association of Work and Organizational Psychology.

Lewis, A. D., Huebner, E. S., Malone, P. S., \& Valois, R. F. (2011). Life satisfaction and student engagement in adolescents. Journal of Youth and Adolescence, 40(3), 249-262. http://dx.doi.org/10.1007/s10964-010-9517-6.

Li, Y., \& Lerner, R. M. (2011). Trajectories of school engagement during adolescence: Implications for grades, depression, delinquency, and substance use. Developmental Psychology, 47(1), 233-247. http://dx.doi.org/10.1037/a0021307.

Lucas, R. E., \& Gohm, C. L. (2000). Age and sex differences in subjective well-being across cultures. In E. Diener, \& E. M. Suh (Eds.), Culture and subjective wellbeing (pp. 291-318). London: MIT Press.

Marques Pinto, A. (2013). Adaptação Poruguesa para alunos do ensino secundário do Maslach Burnout Inventory - Student Survey [Portuguese adaptation of the Maslach Burnout Inventory - Student Survey for secondary school pupils]. Unpublished manuscript. Faculty of Psychology, University of Lisboa, Lisboa.

Martínez, I., Marques Pinto, A., \& Lopes da Silva, A. (2001). Burnout em estudantes do ensino superior [University students burnout]. Revista Portuguesa de Psicologia, 35, 151-167.

Maslach, C., \& Leiter, M. P. (1997). The truth about burnout: How organizations cause personal stress and what to do about it. San Francisco, CA: Jossey-Bass.

Maslach, C., Schaufeli, W., \& Leiter, M. P. (2001). Job burnout. Annual Review of Psychology, 52, $397-422$.

Matos, A. P., André, R. S., Cherpe, S., Rodrigues, D., Figueira, C., \& Marques Pinto, A. (2010). Estudo Psicométrico preliminar da Mental Health Continuum Short Form - for Youth numa amostra de adolescentes portugueses [Preliminary psychometric study of the Mental Health Continuum - Short Form for Youth in a sample of Portuguese students]. Psychologica, 53, 131-156.

McPhee, I., Marks, L., \& Marks, D. (2013). Examining the impact of the apple "iPad" on male and female classroom engagement in a primary school in Scotland. In ICICTE 2013 Proceedings (pp. 443-451).

Moreira, P., Dias, P. C., Vaz, F. M., \& Vaz, J. M. (2013). Predictors of academic performance and school engagement-Integrating persistence, motivation and study skills perspectives using person-centered and variable-centered approaches. Learning and Individual Differences, 24, 117-125. http://dx.doi.org/10. 1016/j.lindif.2012.10.016.

Muthén, L. K., \& Muthén, B. O. (2012). Mplus user's guide. Seventh edition. Los Angeles, CA: Muthén \& Muthén.

Qiao, H., \& Schaufeli, W. (2011). The convergent validity of four burnout measures in a Chinese sample: A confirmatory factor-analytic approach. Applied Psychology, 60(1), 87-111. http://dx.doi.org/10.1111/j.1464-0597.2010.00428.x.

Rees, G., Pople, L., \& Goswami, H. (2011). Understanding children's well-being links between family economic factors and children's subjective well-being: Initial findings from Wave 2 and Wave 3 quarterly surveys. London: Children's Society.

Robbins, S. B., Lauver, K., Le, H., Davis, D., Langley, R., \& Carlstrom, A. (2004). Do psychosocial and study skill factors predict college outcomes? A metaanalysis. Psychological Bulletin, 130(2), 261-288. http://dx.doi.org/10.1037/0033-2909.130.2.261.

Salanova, M., Schaufeli, W., Martínez, I., \& Bresó, E. (2010). How obstacles and facilitators predict academic performance: The mediating role of study burnout and engagement. Anxiety, Stress, \& Coping, 23(1), 53-70. http://dx.doi.org/10.1080/10615800802609965.

Salmela-Aro, K., Kiuru, N., Leskinen, E., \& Nurmi, J. (2009). School Burnout Inventory (SBI): Reliability and validity. European Journal of Psychological Assessment, 25(1), 48-57. http://dx.doi.org/10.1027/1015-5759.25.1.48.

Salmela-Aro, K., Kiuru, N., \& Nurmi, J. (2008). The role of educational track in adolescents' school burnout: A longitudinal study. British Journal of Educational Psychology, 78(4), 663-689. http://dx.doi.org/10.1348/000709908x281628.

Salmela-Aro, K., Savolainen, H., \& Holopainen, L. (2009). Depressive symptoms and school burnout during adolescence: Evidence from two cross-lagged longitudinal studies. Journal of Youth and Adolescence, 38(10), 1316-1327. http://dx.doi.org/10.1007/s10964-008-9334-3.

Salmela-Aro, K., \& Tuominen-Soini, H. (2010). Adolescents' life satisfaction during the transition to post-comprehensive education: Antecedents and consequences. Journal of Happiness Studies, 11(6), 683-701. http://dx.doi.org/10.1007/s10902-009-9156-3.

Salmela-Aro, K., \& Tynkkynen, L. (2012). Gendered pathways in school burnout among adolescents. Journal of Adolescence, 35(4), 929-939. http://dx.doi. org/10.1016/j.adolescence.2012.01.001.

Salmela-Aro, K., \& Upadyaya, K. (2012). The schoolwork engagement inventory: Energy, dedication, and absorption (EDA). European Journal of Psychological Assessment, 28(1), 60-67. http://dx.doi.org/10.1027/1015-5759/a000091.

Salmela-Aro, K., \& Upadyaya, K. (2014a). Developmental trajectories of school burnout: Evidence from two longitudinal studies. Learning and Individual Differences, 36, 60-68. http://dx.doi.org/10.1016/j.lindif.2014.10.016.

Salmela-Aro, K., \& Upadyaya, K. (2014b). School burnout and engagement in the context of demands-resources model. British Journal of Educational Psychology, 84(1), 137-151. http://dx.doi.org/10.1111/bjep.12018. 
Schaufeli, W., \& Bakker, A. B. (2004). Job demands and job resources and their relationship with burnout and engagement: A multiple-sample study. Journal of Organizational Behavior, 25, 293-315. http://dx.doi.org/10.1002/job.248.

Schaufeli, W., Martinez, I. M., Marques Pinto, A., Salanova, M., \& Bakker, A. B. (2002). Burnout and engagement in university students: A cross-national study. Journal of Cross-Cultural Psychology, 33(5), 464-481. http://dx.doi.org/10.1177/0022022102033005003.

Schaufeli, W., Salanova, M., González-Romá, V., \& Bakker, A. B. (2002). The measurement of engagement and burnout: A two sample confirmatory factor analytic approach. Journal of Happiness Studies, 3, 71-92.

Schermelleh-Engel, K., Moosbrugger, H., \& Müller, H. (2003). Evaluating the fit of structural equation models: Tests of significance and descriptive goodnessof-fit measures. Methods of Psychological Research Online, 8(2), 23-74.

Shernoff, D. J., Csikszentmihalyi, M., Schneider, B., \& Shernoff, E. S. (2014). Student engagement in high school classrooms from the perspective of flow theory. In Applications of flow in human development and education: The collected works of Mihaly Csikszentmihalyi (pp. 475-494). DeKalb, IL, United States: CHAP, Department of Educational Psychology and Foundation, Northern Illinois University, Graham Hall. http://dx.doi.org/10.1007/978-94-0179094-9_24.

Suldo, S. M., Shaunessy, E., Thalji, A., Michalowski, J., \& Shaffer, E. (2009). Sources of stress for students in high school college preparatory and general education programs: Group differences and associations with adjustment. Adolescence, 44(176), 925-948.

Symonds, J., Dietrich, J., Chow, A., \& Salmela-Aro, K. (2016). Mental health improves after transition from comprehensive school to vocational education or employment in England: A national cohort study. Developmental Psychology, 52(4), 652-665. http://dx.doi.org/10.1037/a0040118.

Tuominen-Soini, H., \& Salmela-Aro, K. (2014). Schoolwork engagement and burnout among Finnish high school students and young adults: Profiles, progressions, and educational outcomes. Developmental Psychology, 50(3), 649-662. http://dx.doi.org/10.1037/a0033898.

Upadyaya, K., \& Salmela-Aro, K. (2013). Development of school engagement in association with academic success and well-being in varying social contexts: A review of empirical research. European Psychologist, 18(2), 136-147. http://dx.doi.org/10.1027/1016-9040/a000143.

Walburg, V. (2014). Burnout among high school students: A literature review. Children and Youth Services Review, 42, 28-33. http://dx.doi.org/10.1016/j. childyouth.2014.03.020.

Wang, M., Chow, A., Hofkens, T., \& Salmela-Aro, K. (2015). The trajectories of student emotional engagement and school burnout with academic and psychological development: Findings from Finnish adolescents. Learning and Instruction, 36, 57-65. http://dx.doi.org/10.1016/j.learninstruc.2014.11.004.

Wang, M., \& Degol, J. (2014). Staying engaged: Knowledge and research needs in student engagement. Child Development Perspectives, 8(3), 137-143. http:// dx.doi.org/10.1111/cdep.12073.

Weckwerth, A. C., \& Flynn, D. M. (2006). Effect of sex on perceived support and burnout in university students. College Student Journal, 40(2), 237-249.

Willingham, W. W., Pollack, J. M., \& Lewis, C. (2002). Grades and test scores: Accounting for observed differences. Journal of Educational Measurement, 39(1), 1-37. http://dx.doi.org/10.1111/j.1745-3984.2002.tb01133.x.

Yusoff, M. (2010). Stress, stressors and coping strategies among secondary school students in a Malaysian government secondary school. ASEAN Journal of Psychiatry, 11(2), 1-15. 